Article

\title{
Chemical Composition and Antibacterial Activity of Essential Oils from Different Parts of Leonurus japonicus Houtt.
}

Liang Xiong ${ }^{1,2}$, Cheng Peng ${ }^{1,2, *}$, Qin-Mei Zhou ${ }^{1,2}$, Feng Wan ${ }^{2}$, Xiao-Fang Xie ${ }^{1,2}$, Li Guo ${ }^{1,2}$, Xiao-Hong $\mathrm{Li}^{1,2}$, Cheng-Jun $\mathrm{He}^{1,2}$ and Ou Dai ${ }^{1}$

1 State Key Laboratory Breeding Base of Systematic Research, Development and Utilization of Chinese Medicine Resources, Sichuan Province and Ministry of Science and Technology, Chengdu 610075, Sichuan, China; E-Mails: xiling0505@126.com (L.X.); zhqmyx@sina.com (Q.-M.Z.); wanfengcdzy@126.com (F.W.); xxf14544@163.com (X.-F.X.); gli64@sina.com (L.G.); lixiaohong136@126.com (X.-H.L.); heye1217@163.com (C.-J.H.); haiou0505@126.com (O.D.)

2 Pharmacy College, Chengdu University of Traditional Chinese Medicine, Chengdu 610075, Sichuan, China

* Author to whom correspondence should be addressed; E-Mail: pengchengchengdu@126.com; Tel./Fax: +86-028-6180-0018.

Received: 10 December 2012; in revised form: 30 December 2012 / Accepted: 4 January 2013 / Published: 14 January 2013

\begin{abstract}
The herb and fruits of Leonurus japonicus Houtt., named "Yimucao" and "Chongweizi", respectively, in Chinese, have been widely used in China as gynecological medicines. The components of the essential oils obtained by hydrodistillation were investigated by GC-MS. The antibacterial activity of the essential oils was determined by micro-dilution assay. The results showed large variations in the chemical composition and antibacterial activity of the oils. The oil of "Yimucao" showed antibacterial activity against various Gram-positive bacteria and consisted mainly of sesquiterpenes and diterpenes, with phytone, phytol, caryophyllene oxide and $\beta$-caryophyllene being the most significant constituents, whereas the oil of "Chongweizi", mainly made up of bornyl acetate and aliphatic hydrocarbons, was inactive in the antibacterial assay. Further study of the main compounds in "Yimucao oil" showed that $\beta$-caryophyllene had wide-spectrum activity against Gram-positive bacteria.
\end{abstract}


Keywords: Leonurus japonicus; essential oil composition; antibacterial activity; $\beta$-caryophyllene

\section{Introduction}

Leonurus japonicus Houtt. is an annual herbaceous plant of the Lamiaceae family, widely distributed in East Asia. The herb harvested in summer before blossoming and the ripe fruits picked in autumn, commonly referred to as "Yimucao" and "Chongweizi", respectively, in Traditional Chinese Medicine, are both used for regulating menstrual disturbances and invigorating blood circulation [1,2]. Previous bioactivity investigations of the Leonurus genus, including L. persicus, L. japonicus, L. sibiricus and L. heterophyllus, showed that the extracts of aerial parts had anti-inflammatory [3], antibacterial [4-6], anti-platelet aggregation [7], and cytotoxic activities [8]. Even more remarkably, two novel proteins from the seeds of L. japonicus inhibited the growth of both fungi and bacteria [9,10].

Although "Yimucao" and "Chongweizi" are obtained from the same plant and both are used as gynecological medicines, they are harvested in the culture field, circulated on the market, used in the clinic and recorded in China Pharmacopoeia separately. Generally speaking, "Yimucao" are often used to treat acute nephritis, dispel edema and oliguria, whereas "Chongweizi" can be used as a drug or a tea drink for improving vision and reducing blood pressure [1,2]. Thus, the two medicines from the same plant have something in common and some differences in traditional applications. To illustrate the main differences of the chemical components and the antibacterial activity between "Yimucao oil" and "Chongweizi oil", and search for the major active ingredients, we used GC-MS to determine the contents of the oils and applied micro-dilution assay to evaluate the antibacterial activity of the oils and the isolates. This paper describes how much difference there is between "Yimucao oil" and "Chongweizi oil" and what the probable antibacterial compositions in the oils are.

\section{Results}

\subsection{Antibacterial Activity of "Yimucao Oil" and "Chongweizi Oil"}

The essential oils were obtained by hydrodistillation from air dried "Yimucao" and "Chongweizi", respectively, and their antibacterial activity was subsequently assayed by the micro-dilution assay. In our study, 14 standard bacterial strains found in human beings and animals were used, and the MIC values of the oils on these bacterial strains were tested to determine their antibacterial potential (Table 1).

The results showed that "Chongweizi oil" was inactive in the antibacterial assay (MIC $>3.2 \mathrm{mg} / \mathrm{mL}$ ), while "Yimucao oil" exhibited antibacterial activity against several Gram-positive bacteria, but was ineffective against Gram-negative bacteria. The MICs of "Yimucao oil" were $0.2 \mathrm{mg} / \mathrm{mL}$ against M. caseolyticus, $0.4 \mathrm{mg} / \mathrm{mL}$ against $S$. epidermidis and E. faecalis, and $1.6 \mathrm{mg} / \mathrm{mL}$ against $S$. aureus, methicillin-resistant $S$. aureus, $S$. saprophyticus and E. faecium. 
Table 1. Antibacterial activity of "Yimucao oil" and "Chongweizi oil".

\begin{tabular}{|c|c|c|c|c|}
\hline \multirow{2}{*}{ NO } & \multirow{2}{*}{ Bacterial species } & \multirow{2}{*}{ Source } & \multicolumn{2}{|c|}{$\mathrm{MIC}^{\mathrm{a}}(\mathrm{mg} / \mathrm{mL})$} \\
\hline & & & "Yimucao oil"" & "Chongweizi oil" \\
\hline & Gram-positive bacteria & & & \\
\hline 1 & Staphylococcus aureus & ATCC $^{\mathrm{b}} 25923$ & 1.6 & $-^{\mathrm{d}}$ \\
\hline 2 & Staphylococcus aureus & $\mathrm{CIS}^{\mathrm{c}}$ & 1.6 & - \\
\hline 3 & methicillin-resistant Staphylococcus aureus & ATCC 43300 & 1.6 & - \\
\hline 4 & Staphylococcus epidermidis & CIS & 0.4 & - \\
\hline 5 & Staphylococcus saprophyticus & CIS & 1.6 & - \\
\hline 6 & Macrococcus caseolyticus & CIS & 0.2 & - \\
\hline 7 & Enterococcus faecium & CIS & 1.6 & - \\
\hline \multirow[t]{2}{*}{8} & Enterococcus faecalis & CIS & 0.4 & - \\
\hline & Gram-negative bacteria & & & \\
\hline 9 & Escherichia coli & ATCC 25922 & - & - \\
\hline 10 & Pseudomonas aeruginosa & CIS & - & - \\
\hline 11 & Klebsiella pneumoniae & CIS & - & - \\
\hline 12 & Moraxella catarrhalis & CIS & - & - \\
\hline 13 & Enterobacter cloacae & CIS & - & - \\
\hline 14 & Acinetobacter lwoffii & CIS & - & - \\
\hline
\end{tabular}

\subsection{Components of "Yimucao Oil" and "Chongweizi Oil"}

The essential oils from air dried "Yimucao" and "Chongweizi" were subsequently analyzed by GC and GC/MS systems. In total, 46 ("Yimucao oil") and 49 ("Chongweizi oil") constituents were identified and quantified respectively (Table 2).

Table 2. Chemical composition of "Yimucao oil" and "Chongweizi oil".

\begin{tabular}{|c|c|c|c|c|}
\hline \multirow{2}{*}{ NO } & \multirow{2}{*}{ Compounds } & \multirow{2}{*}{$\mathbf{R I}^{\mathrm{a}}$} & \multicolumn{2}{|c|}{ Area (\%) } \\
\hline & & & Herb oil ("Yimucao") & Fruits oil ("Chongweizi") \\
\hline & Monoterpenes & & & \\
\hline 1 & 1,5,8-p-Menthatriene & 1106 & 0.64 & - \\
\hline 2 & Menthone & 1150 & 0.34 & - \\
\hline 3 & $p$-Menth-4-en-3-one & 1240 & 0.57 & 0.22 \\
\hline 4 & Menthol & 1177 & $\operatorname{tr}^{b}$ & 0.61 \\
\hline 5 & 4-Terpineol & 1170 & 0.41 & 0.20 \\
\hline 6 & $\beta$-Terpineol & 1160 & 0.30 & - \\
\hline 7 & Perillyl acetate & 1438 & - & 2.17 \\
\hline 8 & Camphor & 1140 & 0.80 & 0.43 \\
\hline 9 & Borneol & 1172 & 0.76 & 0.66 \\
\hline 10 & Bornyl acetate & 1282 & - & 7.33 \\
\hline 11 & Bornyl acrylate & 1371 & - & 1.81 \\
\hline 12 & Camphene & 1066 & 0.64 & 1.32 \\
\hline 13 & $\alpha$-Pinene & 936 & 0.83 & 0.36 \\
\hline 14 & $\alpha$-Pyronene & 1129 & 1.59 & - \\
\hline
\end{tabular}


Table 2. Cont.

\begin{tabular}{|c|c|c|c|c|}
\hline \multirow{2}{*}{ NO } & \multirow{2}{*}{ Compounds } & \multirow{2}{*}{$\mathbf{R I}^{\mathrm{a}}$} & \multicolumn{2}{|c|}{ Area (\%) } \\
\hline & & & Herb oil ("Yimucao") & Fruits oil ("Chongweizi") \\
\hline 15 & $\alpha$-Fenchene & 941 & 0.40 & - \\
\hline 16 & Elsholtzione & 1200 & 0.54 & - \\
\hline \multirow[t]{2}{*}{$\sum$} & & & 7.82 & 15.11 \\
\hline & Sesquiterpenes & & & \\
\hline 17 & $\beta$-Caryophyllene & 1422 & 9.89 & 1.72 \\
\hline 18 & Caryophyllene oxide & 1579 & 11.49 & 0.53 \\
\hline 19 & Isocaryophyllene & 1445 & 3.00 & - \\
\hline 20 & $\alpha$-Caryophyllene & 1452 & 3.38 & 0.52 \\
\hline 21 & Aromadendrane & 1465 & 1.21 & $\operatorname{tr}$ \\
\hline 22 & Dehydroaromadendrane & 1460 & 1.18 & $\operatorname{tr}$ \\
\hline 23 & Aromadendrene & 1439 & 1.31 & 0.37 \\
\hline 24 & Palustrol & 1588 & 0.86 & - \\
\hline 25 & Spathulenol & 1573 & 5.31 & - \\
\hline 26 & $\alpha$-Muurolene & 1495 & $\operatorname{tr}$ & 0.85 \\
\hline 27 & $\delta$-Cadinene & 1525 & 1.73 & 2.66 \\
\hline 28 & $\gamma$-Cadinene & 1515 & $\operatorname{tr}$ & 0.67 \\
\hline 29 & Germacrene D & 1480 & 1.66 & - \\
\hline 30 & $\alpha$-Copaene & 1380 & 0.71 & - \\
\hline 31 & $\beta$-Endesmene & 1473 & 0.68 & - \\
\hline 32 & $\beta$-Bourbonene & 1383 & 0.89 & - \\
\hline 33 & $\beta$-Patchoulene & 1390 & - & 1.05 \\
\hline 34 & Patchouli alcohol & 1658 & 0.70 & 2.08 \\
\hline 35 & $\beta$-Cubebene & 1350 & 0.38 & - \\
\hline 36 & $\beta$-Elemene & 1395 & 0.21 & - \\
\hline 37 & Irisone & 1460 & 0.78 & $\operatorname{tr}$ \\
\hline \multirow[t]{2}{*}{$\sum$} & & & 45.37 & 10.45 \\
\hline & Diterpenes & & & \\
\hline 38 & Phytol & 2100 & 13.75 & 2.23 \\
\hline 39 & Phytone & 1830 & 19.02 & $\operatorname{tr}$ \\
\hline 40 & Isopimara-8,15-diene & 1952 & - & 2.90 \\
\hline 41 & Dehydroabietane & 2078 & - & 3.32 \\
\hline \multirow[t]{2}{*}{$\Sigma$} & & & 32.77 & 8.45 \\
\hline & Aliphatic compounds & & & \\
\hline 42 & $n$-Dodecane & 1200 & $\operatorname{tr}$ & 1.17 \\
\hline 43 & $n$-Tridecane & 1298 & $\operatorname{tr}$ & 7.72 \\
\hline 44 & 2-Methyldecane & 1061 & - & 0.59 \\
\hline 45 & $n$-Tetradecane & 1401 & 0.48 & 1.57 \\
\hline 46 & $n$-Pentadecane & 1500 & - & 4.36 \\
\hline 47 & $n$-Hexadecane & 1600 & $\operatorname{tr}$ & 9.65 \\
\hline 48 & $n$-Heptadecane & 1706 & - & 1.01 \\
\hline 49 & $n$-Octadecane & 1799 & - & 0.37 \\
\hline 50 & $n$-Nonadecane & 1903 & - & 1.31 \\
\hline 51 & $n$-Docosane & 2200 & 0.45 & 2.44 \\
\hline
\end{tabular}


Table 2. Cont.

\begin{tabular}{|c|c|c|c|c|}
\hline \multirow{2}{*}{ NO } & \multirow{2}{*}{ Compounds } & \multirow{2}{*}{$\mathbf{R I}^{\mathrm{a}}$} & \multicolumn{2}{|c|}{ Area (\%) } \\
\hline & & & Herb oil ("Yimucao") & Fruits oil ("Chongweizi") \\
\hline 52 & Artemisia triene & 930 & - & 2.00 \\
\hline 53 & 1-Dodecene & 1195 & - & 0.51 \\
\hline 54 & Tetradecenal & 1588 & $\operatorname{tr}$ & 0.73 \\
\hline 55 & (Z)-7-Hexadecenal & 1806 & - & 0.78 \\
\hline 56 & Methyl palmitate & 1882 & 0.93 & 1.33 \\
\hline 57 & Methyl isopalmitate & 1818 & $\operatorname{tr}$ & 1.33 \\
\hline 58 & Methyl octadecenoate & 2135 & 0.79 & 2.61 \\
\hline 59 & Methyl linoleate & 2090 & 0.45 & 2.39 \\
\hline 60 & Methyl linolelaidate & 2100 & - & 1.17 \\
\hline \multirow[t]{2}{*}{$\sum$} & & & 3.10 & 43.04 \\
\hline & Other compounds & & & \\
\hline 61 & $1,2,3,4,5,8$-Hexahydronaphthalene & 1146 & - & 2.58 \\
\hline 62 & benzyl benzoate & 1732 & 0.31 & 0.62 \\
\hline 63 & Diisobutyl phthalate & 1906 & - & 2.75 \\
\hline 64 & 4-Hydroxy-3-tertbutylanisole & 1415 & - & 0.37 \\
\hline$\sum$ & & & 0.31 & 6.32 \\
\hline
\end{tabular}

${ }^{a}$ RI: Retention index on a HP-5 MS column; ${ }^{b}$ tr: trace $<0.1 \%$.

"Yimucao oil" was mainly made up of diterpenes (32.77\%) and sesquiterpenes (45.37\%), with phytone (19.02\%), phytol (13.75\%), caryophyllene oxide (11.49\%) and $\beta$-caryophyllene $(9.89 \%)$ being the most significant constituents. Other sesquiterpenes that were present in appreciable amounts were spathulenol (5.31\%), $\alpha$-caryophyllene (3.38\%) and isocaryophyllene (3.00\%). The main structural types were found to belong to the caryophyllane, aromadendrane and cadinane classes, which accounted for $41.73 \%$ of the total oil (Figure 1). In addition, monoterpenes constituted $7.82 \%$ of this oil, with a prevalence of menthane and camphane compounds (3.82\%), among which oxygenated monoterpenes predominated (Figure 1). Ten aliphatic compounds were found in "Yimucao oil" at low percentages of less than 1\%. Unlike the "Yimucao oil", "Chongweizi oil" was characterized by large amounts of aliphatic compounds (43.04\%), including 12 aliphatic hydrocarbons, two aldehydes and five esters. Among them, aliphatic hydrocarbons constituted $32.7 \%$ of the "Chongweizi oill", with the most abundant component being $n$-hexadecane $(9.65 \%)$, followed by $n$-tridecane $(7.72 \%)$ and $n$-pentadecane (4.36\%), most of which were not detected in the "Yimucao oil". In addition to aliphatic compounds, the monoterpene fraction was also noteworthy $(15.11 \%)$, with bornyl acetate $(7.33 \%)$ and bornyl acrylate (1.81\%) as the main constituents, which were absent in the "Yimucao oil". As regards sesquiterpenes and diterpenes of the "Chongweizi oil", the fractions were relatively small when compared to the "Yimucao oil", accounting for only $10.45 \%$ and $8.45 \%$, respectively. It is particularly worth mentioning that caryophyllenes, the major compounds of "Yimucao oil", were present in minor concentrations less than $2 \%$ in "Chongweizi oil". 
Figure 1. Main monoterpenes (A) and sesquiterpenes (B) of essential oil from L. japonicus.
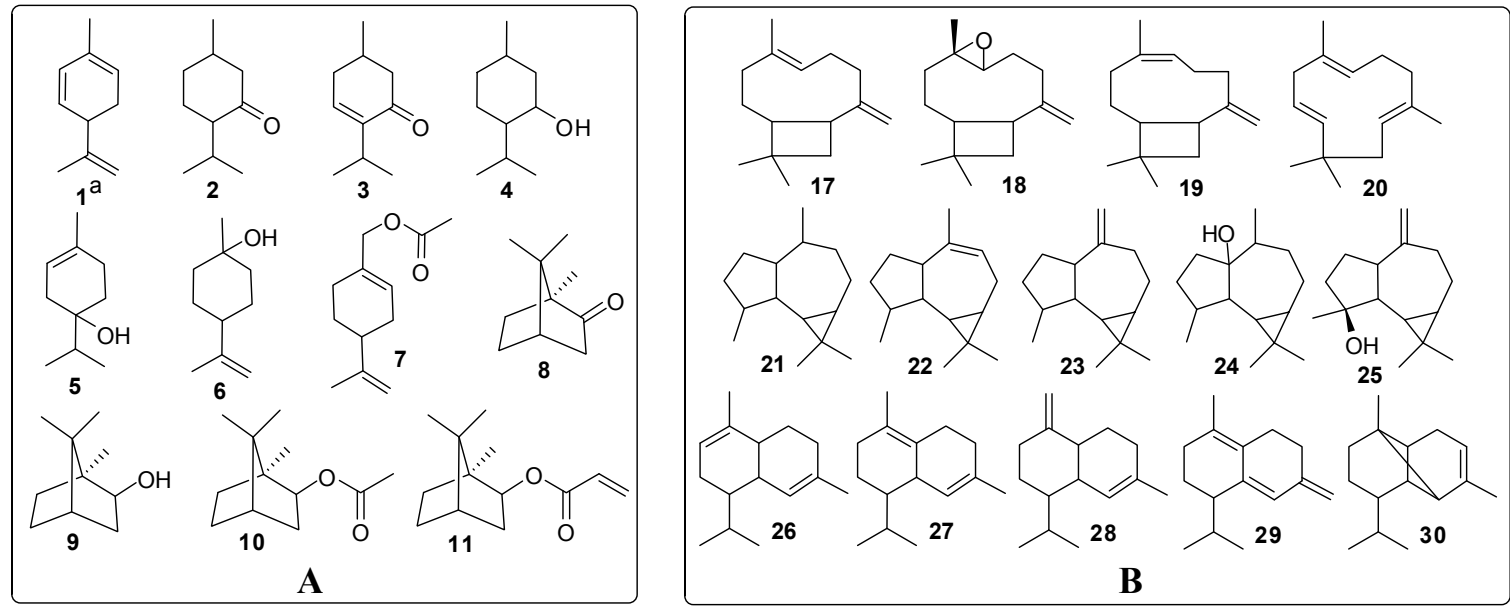

${ }^{\text {a }}$ The number of the compounds was the same as that in Table 2.

Thus, according to the GC and CG/MS analyses, the chemical components of "Yimucao oil" and "Chongweizi oil" were quite different. The "Yimucao oil" was mainly comprised sesquiterpenes and diterpenes, while "Chongweizi oil" was rich in aliphatic compounds, particularly aliphatic hydrocarbons. The result suggested that the significant difference in antibacterial activity of essential oils was relevant to the large variations in the composition.

\subsection{Antibacterial Activity of the Main Compounds in "Yimucao Oil"}

Further investigation on the chemical constituents of "Yimucao Oil" resulted in the isolation and identification of caryophyllene oxide (18) [11] and phytol (38) [12]. Their structures were elucidated by spectroscopic analyses, including HR-ESIMS and NMR techniques. Subsequent study on the antibacterial activity of the main compounds 17, 18 and 38 showed their MIC values against nine bacterial strains (Table 3 ).

Table 3. Antibacterial activity of compounds 17,18 and 38 .

\begin{tabular}{|c|c|c|c|c|c|c|c|c|}
\hline \multirow[b]{2}{*}{ NO } & \multirow[b]{2}{*}{ Bacterial species } & \multirow[b]{2}{*}{ Source } & \multicolumn{2}{|c|}{17} & \multicolumn{2}{|c|}{18} & \multicolumn{2}{|c|}{38} \\
\hline & & & $\begin{array}{c}\text { MIC } \\
(\mathrm{mg} / \mathrm{mL}) \\
\end{array}$ & $\begin{array}{c}\text { MBC } \\
(\mathrm{mg} / \mathrm{mL})\end{array}$ & $\begin{array}{c}\text { MIC } \\
(\mathrm{mg} / \mathrm{mL}) \\
\end{array}$ & $\begin{array}{c}\text { MBC } \\
(\mathrm{mg} / \mathrm{mL}) \\
\end{array}$ & $\begin{array}{c}\text { MIC } \\
(\mathrm{mg} / \mathrm{mL}) \\
\end{array}$ & $\begin{array}{c}\text { MBC } \\
(\mathrm{mg} / \mathrm{mL})\end{array}$ \\
\hline 1 & Staphylococcus aureus & $\begin{array}{l}\text { ATCC } \\
25923\end{array}$ & 0.256 & 0.256 & $-^{\mathrm{a}}$ & - & - & - \\
\hline 2 & Staphylococcus aureus & CIS & 0.256 & 0.256 & - & - & - & - \\
\hline 3 & $\begin{array}{l}\text { methicillin-resistant } \\
\text { Staphylococcus aureus }\end{array}$ & $\begin{array}{l}\text { ATCC } \\
43300\end{array}$ & 0.256 & 0.256 & - & - & - & - \\
\hline 4 & $\begin{array}{l}\text { methicillin-resistant } \\
\text { Staphylococcus aureus }\end{array}$ & CIS & 0.256 & 0.256 & - & - & - & - \\
\hline 5 & $\begin{array}{l}\text { Staphylococcus } \\
\text { epidermidis }\end{array}$ & CIS & 0.128 & 0.256 & - & - & - & - \\
\hline 6 & $\begin{array}{l}\text { Staphylococcus } \\
\text { auricularis }\end{array}$ & CIS & 0.032 & 0.128 & 0.128 & 0.256 & 0.128 & 0.512 \\
\hline 7 & $\begin{array}{c}\text { Macrococcus } \\
\text { caseolyticus }\end{array}$ & CIS & 0.032 & 0.128 & 0.128 & 0.256 & 0.128 & 0.512 \\
\hline 8 & Enterococcus faecium & CIS & 0.032 & 0.064 & 0.256 & 0.256 & - & - \\
\hline 9 & Enterococcus faecalis & CIS & 0.032 & 0.064 & 0.256 & $>0.512$ & - & - \\
\hline
\end{tabular}


Compound 17 showed wide-spectrum activity against Gram-positive bacteria, including S. aureus, methicillin-resistant S. aureus, S. epidermidis, S. auricularis, M. caseolyticus, E. faecium and E. faecalis, especially for the last four strains. The MIC values ranged from 0.032 to $0.256 \mathrm{mg} / \mathrm{mL}$, and the MBC values were similar or 2-4 folds higher than MIC values. Compound 18 showed only activity against $S$. auricularis, M. caseolyticus, E. faecium and E. faecalis, while $\mathbf{3 8}$ was inactive against Gram-positive bacteria, except for S. auricularis and M. caseolyticus (MICs, each $0.128 \mathrm{mg} / \mathrm{mL}$ ).

\section{Discussion}

"Yimucao" and "Chongweizi", derived from different parts of L. japonicus, are two common drugs in Traditional Chinese Medicine. This work provided the first report of the comparison of the chemical composition and bioactivity between "Yimucao" and "Chongweizi". GC-MS analyses of the volatile constituents showed large variations between "Yimucao oil" and "Chongweizi oil". The most representative compounds in "Yimucao oil" were sesquiterpenes (45.37\%) and diterpenes (32.77\%), followed by monoterpenes $(7.82 \%)$ and a small amount of aliphatic compounds $(3.10 \%)$. However, "Chongweizi oil" is predominantly composed by aliphatic compounds (43.04\%) and monoterpenes (15.11\%), followed by sesquiterpenes $(10.45 \%)$ and diterpenes $(8.45 \%)$ represent the minor groups in this mixture. The results indicated that the variability in the composition of essential oils depend essentially upon the medicinal parts and the harvest season $[13,14]$.

Then the essential oils also showed a very diverse antibacterial effect. The "Yimucao oil" exhibited antibacterial activity against several Gram-positive bacteria, while the "Chongweizi oil" was inactive in the assay. According to the above results, we could infer that the antibacterial activity of essential oil from L. japonicus may be due to the abundant sesquiterpenes and diterpenes rather than aliphatic compounds, especially due to caryophyllenes (accounting for $27.76 \%$ of the total oil). Although the "Chongweizi oil" showed no effect against the bacterial strains in our study, innovative researches about "Chongweizi" have led to the purification of two antimicrobial proteins $[9,10]$. These implied that "Chongweizi" is also an effective antibacterial drug, and the activity may be related to the rich proteins instead of essential oil.

Further investigation on the isolated compounds of "Yimucao oil" showed that $\beta$-caryophyllene had favorable antibacterial activity against Gram-positive bacteria, with MICs from 0.032 to $0.256 \mathrm{mg} / \mathrm{mL}$ and MBCs from 0.064 to $0.256 \mathrm{mg} / \mathrm{mL}$. The results were consistent with the earlier reports [15-17]. In particular, $\beta$-caryophyllene was reported to show significant antibacterial activity against $E$. faecium and E. faecalis, the MICs (each $0.025 \mathrm{mg} / \mathrm{mL}$ ) in the previous investigation were very similar to those in this study (each $0.032 \mathrm{mg} / \mathrm{mL}$ ). In addition, the antibacterial assay displayed that $\beta$-caryophyllene was inactive against Gram-negative bacteria, including Enterobacter cloacae, Escherichia coli, Moraxella catarrhalis, Klebsiella pneumoniae and Pseudomonas maltophila, whereas some reports found $\beta$-caryophyllene to be active against other Gram-negative bacteria strains, such as Achromobacter xylosoxidans denitrificans, Escherichia coli, Chryseobacterium indologenes, Citrobacter freundii and Flavimonas oryzihabitans. However, the MICs against E. coli were obvious different among the reports $(0.625-12.8 \mathrm{mg} / \mathrm{mL})$ [15-19]. This may be the consequence of a problem with the solubility of $\beta$-caryophyllene, which we also experienced during our study. 


\section{Experimental}

\subsection{General}

GC and GC-MS were measured on an Agilent 7890A/5975C spectrometer. NMR spectra were recorded on a Bruker-AV-400 spectrometer. ESIMS were determined on a Waters Synapt $\mathrm{G}_{2}$ HDMS instrument. Column chromatography was performed with silica gel (200-300 mesh, Jiangyou Silical Gel Development Co., Yantai, China), and Sephadex LH-20 (Amersham Pharmacia Biotech AB, Uppsala, Sweden). Mueller-Hinton agar and McFarland Standard were purchased from OXOID (Basingstoke, UK) and bioMerieux Inc. (Marcy-l'Etoile, France), respectively. $\beta$-Caryophyllene was purchased from J\&K Scientific Ltd. (Beijing, China).

\subsection{Plant Material}

The herb of L. japonicus ("Yimucao") was collected in May of 2012 from the field in Wenjiang District, Chengdu City, Sichuan Province, China. The ripe fruits of L. japonicus ("Chongweizi”) were gathered in August of 2012 from the same field. Plant identity was verified by Prof. Min Li (Chengdu University of TCM, Sichuan, China). Voucher specimens were deposited at the School of Pharmacy, Chengdu University of TCM.

\subsection{Volatile Oil Extraction}

Air dried and powdered herb $(5 \mathrm{~kg})$ and fruits $(5 \mathrm{~kg})$ were separately subjected to hydrodistillation for $10 \mathrm{~h}$ using a modified Clevenger type apparatus with a water-cooled oil receiver to obtain the essential oils. The oils were dried over anhydrous sodium sulfate and kept in air tight glass bottles in a refrigerator for further experiments.

\subsection{Antibacterial Activity Experiments}

Three bacterial strains, S. aureus (ATCC25923), methicillin-resistant S. aureus (ATCC43300) and E. coli (ATCC25922) were obtained from the American Type Culture Collection (ATCC, Rockefeller, MD, USA). The other bacterial strains were clinically isolated and obtained from the Teaching Hospital of Chengdu University of TCM. These strains included Gram-positive $\left(\mathrm{G}^{+}\right)$bacteria: S. aureus, S. epidermidis, S. saprophyticus, M. caseolyticus, E. faecium and E. faecalis; and Gram-negative (G $\mathrm{G}^{-}$bacteria: P. aeruginosa, K. pneumoniae, M. catarrhalis, E. cloacae and A. lwoffii (Table 1). The in vitro antibacterial activity was determined by the standard agar dilution method, according to NCCLS (National Committee for Clinical Laboratory Standard) [20]. Volatile oil was dissolved in DMSO to a concentration of $3.2 \mathrm{mg} / \mathrm{mL}$, and then distributed at various concentrations in triplicate with a volume of $100 \mu \mathrm{L}$ in turbidity tubes. Bacterial suspension $(5 \mu \mathrm{L})$ with a density of $1 \times 10^{6} \mathrm{CFU} / \mathrm{mL}$ in Mueller-Hinton $(\mathrm{MH})$ agar was added to each tube. Positive control was a suspension of bacteria in $1 \mathrm{~mL}$ of $\mathrm{MH}$ agar, and negative control was medium without bacteria. The MIC values (minimum inhibitory concentration at which the microbes failed to grow into a visible spot) were determined after incubation at $37^{\circ} \mathrm{C}$ for $24 \mathrm{~h}$. 


\subsection{Analysis of Components}

An Agilent 7890A/5975C Gas Chromatography-Mass Spectroscopy system equipped with GC-MSD was used for analysis with ionization achieved by electron impact at $70 \mathrm{eV}$. The HP-5 MS quartz capillary column $(30 \mathrm{~m} \times 0.25 \mathrm{~mm}, 0.25 \mu \mathrm{m}$ film thickness) was used with helium (purity $99.999 \%$ ) as carrier gas at a flow rate of $1.0 \mathrm{~mL} / \mathrm{min}$. Experimental conditions for GC analysis of volatile oil were: injection port temperature, $280{ }^{\circ} \mathrm{C}$; column oven temperature, $100{ }^{\circ} \mathrm{C}$ for 5 min and programmed at $4{ }^{\circ} \mathrm{C} / \mathrm{min}$ to $160{ }^{\circ} \mathrm{C}$, kept constant at $160^{\circ} \mathrm{C}$ for $10 \mathrm{~min}$, then programmed at $5{ }^{\circ} \mathrm{C} / \mathrm{min}$ to $240{ }^{\circ} \mathrm{C} ; 1 \mu \mathrm{L}$ injection volume, and split ratio adjusted at 20:1. The mass spectrum of each peak was recorded in the total ion current mode of the mass spectrometer within a mass range of 20 to 800 . Identification of oil constituents was achieved using NIST08 mass spectral database.

\subsection{Isolation of Components from "Yimucao Oil"}

The "Yimucao Oil" (4.6 g) was subjected to silica gel CC using a gradient elution of $n$-hexane-EtOAc $(100: 0-5: 1)$ to afford seven fractions (Fr. A-G). Fr. C was subjected to Sephadex LH-20 (petroleum ether- $\left.\mathrm{CHCl}_{3}-\mathrm{MeOH}, 5: 5: 1\right)$ to give four subfractions $(\mathrm{C} 1-\mathrm{C} 4)$. The successive separation of $\mathrm{C} 1$ with silica gel ( $n$-hexane- $\mathrm{Et}_{2} \mathrm{O}$ 50:1) yielded $\mathrm{C} 1-1-\mathrm{C} 1-6 . \mathrm{C} 1-2$ was further purified via PTLC (petroleum ether-EtOAc 15:1) to afford $\mathbf{1 8}$ (28 mg), and C1-3 was subjected to PTLC (petroleum ether-EtOAc 8:1) followed by reversed-phase semipreparative $\mathrm{HPLC}\left(94 \% \mathrm{MeOH}\right.$ in $\mathrm{H}_{2} \mathrm{O}$ ) to yield 38 (36 mg).

Caryophyllene oxide (18): Colorless oil; ESI-MS $m / z 221.2[\mathrm{M}+\mathrm{H}]^{+}, 243.2[\mathrm{M}+\mathrm{Na}]^{+}$; HRESI-MS: $m / z$ $243.1729[\mathrm{M}+\mathrm{Na}]^{+}$(calcd for $\left.\mathrm{C}_{15} \mathrm{H}_{24} \mathrm{O}, 243.1725\right) ;{ }^{1} \mathrm{H}-\mathrm{NMR}\left(400 \mathrm{MHz}, \mathrm{CDCl}_{3}\right) \delta: 4.96(1 \mathrm{H}$, brs, H-13a), 4.85 (1H, brs, H-13b), 2.86 (1H, dd, $J=10.4,4.0 \mathrm{~Hz}, \mathrm{H}-5), 2.61$ (1H, q, $J=7.6 \mathrm{~Hz}, \mathrm{H}-9), 1.19$ $\left(3 \mathrm{H}, \mathrm{s}, \mathrm{H}_{3}-12\right), 0.99$ (3H, s, H3-15), $0.97\left(3 \mathrm{H}, \mathrm{s}, \mathrm{H}_{3}-14\right) ;{ }^{13} \mathrm{C}-\mathrm{NMR}\left(100 \mathrm{MHz}, \mathrm{CDCl}_{3}\right)$ 8: $51.0(\mathrm{C}-1)$, 27.3 (C-2), 39.4 (C-3), 59.7 (C-4), 63.8 (C-5), 30.0 (C-6), 29.7 (C-7), 151.8 (C-8), 48.8 (C-9), 39.9 (C-10), 34.1 (C-11), 17.0 (C-12), 112.8 (C-13), 29.7 (C-14), 21.7 (C-15).

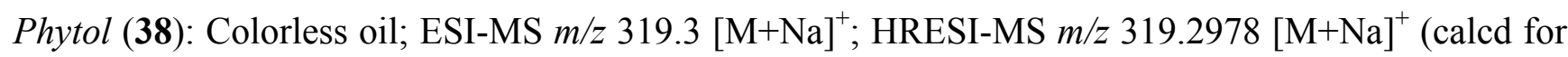
$\left.\mathrm{C}_{20} \mathrm{H}_{40} \mathrm{ONa}, 319.2977\right)$; ${ }^{1} \mathrm{H}-\mathrm{NMR}\left(500 \mathrm{MHz}, \mathrm{CDCl}_{3}\right) \delta$ : $5.41(1 \mathrm{H}, \mathrm{t}, J=7.0 \mathrm{~Hz}, \mathrm{H}-2), 4.15(2 \mathrm{H}, \mathrm{d}$, $\left.J=7.0 \mathrm{~Hz}, \mathrm{H}_{2}-1\right), 1.99(2 \mathrm{H}, \mathrm{m}, \mathrm{H}-4), 1.67\left(3 \mathrm{H}, \mathrm{s}, \mathrm{H}_{3}-20\right), 0.87,0.86\left(6 \mathrm{H}, \mathrm{s}, \mathrm{H}_{3}-18,19\right), 0.85,0.84(6 \mathrm{H}$, $\left.\mathrm{d}, J=6.5 \mathrm{~Hz}, \mathrm{H}_{3}-16,17\right) ;{ }^{13} \mathrm{C}-\mathrm{NMR}\left(125 \mathrm{MHz}, \mathrm{CDCl}_{3}\right) \delta: 59.4(\mathrm{C}-1), 123.1(\mathrm{C}-2), 140.3(\mathrm{C}-3), 39.9$ (C-4), 25.1 (C-5), 36.7 (C-6), 32.8 (C-7), 37.4 (C-8), 24.5 (C-9), 37.4 (C-10), 32.7 (C-11), 37.3 (C-12), 24.8 (C-13), 39.4 (C-14), 28.0 (C-15), 22.7 (C-16, 17), 19.7 (C-18, 19), 16.2 (C-20).

\section{Conclusions}

It can be concluded that $\beta$-caryophyllene is in fact the main antibacterial component in "Yimucao oil". However, it is very difficult to attribute the biological activities of a total essential oil to one or a few active principles, because the minor compounds also may be effective. In addition, it is known that the synergistic or antagonistic effect of a compound present in minor percentage in a mixture has to be considered as well [21]. Thus, further extensive studies on the antibacterial activity of "Yimucao oil" are necessary. 


\section{Acknowledgments}

Financial support from the National Key Technology R\&D Program for the "Eleventh Five-Year" Plan of China (grant No. 2009BAI84B00) is acknowledged.

\section{References}

1. Jiangsu New Medical College. Dictionary of Traditional Chinese Medicine; Shanghai Science and Technology Publishing House: Shanghai, China, 1995; pp. 1609-1610 and 1954-1956.

2. Li, Y.X.; Chen, Z.; Feng, Z.M.; Yang, Y.N.; Jiang, J.S.; Zhang, P.C. Hepatoprotective glycosides from Leonurus japonicus Houtt.. Carbohydr. Res. 2012, 348, 42-46.

3. Tasdemir, D.; Scapozza, L.; Zerbe, O.; Linden, A.; Çalis, I.; Sticher, O. Iridoid glycosides of Leonurus persicus. J. Nat. Prod. 1999, 62, 811-816.

4. De Souza, G.C.; Haas, A.P.S.; Von Poser, G.L.; Schapoval, E.E.S.; Elisabetsky, E. Ethnoparmacological studies of antimicrobial remedies in the south of Brazil. J. Ethnopharmacol. 2004, 90, 135-143.

5. Yang, Z.C.; Yang, X.S.; Wang, B.C.; Hao, X.J. Screening of antibiotic resistant inhibitors from traditional Chinese Medicines against two different strains of Staphylococcus aureus. Nat. Prod. Res. Dev. 2005, 17, 700-703.

6. Yang, H.X.; Ma, Q.Y.; Zheng, Z.F. Study on antimicrobial activities of the extract of seven kinds of Chinese Herbs rich in alkaloid. J. Zhengzhou Univ. (Med. Sci.) 2004, 39, 859-861.

7. Lee, C.M.; Jiang, L.M.; Shang, H.S.; Hon, P.M.; He, Y.; Wong, H.N.C. Prehispanolone, a novel platelet activating factor receptor antagonist from Leonurus heterophyllus. Br. J. Pharmacol. 1991, 108, 1719-1724.

8. Satoh, M.; Satoh, Y.; Isobe, K.; Fujimoto, Y. Studies on the constituents of Leonurus sibiricus L. Chem. Pharm. Bull. 2003, 51, 341-342.

9. Yang, X.Y.; Xiao, Y.H.; Wang, X.W.; Pei, Y. Expression of a novel small antimicrobial protein from the seeds of motherwort (Leonurus japonicus) confers disease resistance in tobacco. Appl. Environ. Microbiol. 2007, 73, 939-946.

10. Yang, X.Y.; Wang, X.W.; Li, X.B.; Zhang, B.B.; Xiao, Y.H.; Li, D.M.; Xie, C.J.; Pei, Y. Characterization and expression of an nsLTPs-like antimicrobial protein gene from motherwort (Leonurus japonicus). Plant Cell Rep. 2008, 27, 759-766.

11. De Oliveira Chaves, M.C.; de Oliveira Santos, B.V. Constituents from Piper marginatum fruits. Fitoterapia 2002, 73, 547-549.

12. Brown, G.D. Phytene-1,2-diol from Artemisia annua. Phytochemistry 1994, 36, 1553-1554.

13. Besbes, M.; Omri, A.; Cheraif, I.; Daami, M.; Jannet, H.B.; Mastouri, M.; Aouni, M.; Selmi, B. Chemical composition and antimicrobial activity of essential oils from Scabiosa arenaria Forssk. growing wild in Tunisia. Chem. Biodiver. 2012, 9, 829-839.

14. Hui, R.H.; Hou, D.Y.; Li, T.C.; Liu, X.Y.; Li, X.C. Study on the volatile constituents in leaf of Syringa oblata Lindl. at different season. J. Chin. Mass Spectrom. Soc. 2008, 29, 18-20. 
15. Rasoarivelo, S.T.R.; Grougnet, R.; Vérité, P.; Lecsö, M.; Butel, M.J.; Tillequin, F.; Guillou, C.R.; Deguin, B. Chemical composition and antimicrobial activity of the essential oils of Anthospermum emirnense and Anthospermum perrieri (Rubiaceae). Chem. Biodiver. 2011, 8, 145-154.

16. Maggi, F.; Cecchini, C.; Cresci, A.; Coman, M.M.; Tirillini, B.; Sagratini, G.; Papa, F. Chemical composition and antimicrobial activity of the essential oil from Ferula glauca L. (F. communis L. subsp. glauca) growing in Marche (central Italy). Fitoterapia 2009, 80, 68-72.

17. Skaltsa, H.D.; Demetzos, C.; Lazari, D.; Sokovic, M. Essential oil analysis and antimicrobial activity of eight Stachys species from Greece. Phytochemistry 2003, 64, 743-752.

18. Tzakou, O.; Skaltsa, H. Composition and antibacterial activity of the essential oil of Satureja parnassica subsp. parnassica. Planta Med. 2003, 69, 282-284.

19. Cha, J.D.; Jeong, M.R.; Choi, H.J.; Jeong, S.I.; Moon, S.E.; Yun, S.I.; Kim, Y.H.; Kil, B.S.; Song, Y.H. Chemical composition and antimicrobial activity of the essential oil of Artemisia lavandulaefolia. Planta Med. 2005, 71, 575-577.

20. National Committee for Clinical Laboratory Standards (NCCLS). Methods for Dilution Antimicrobial Susceptibility Tests for Bacteria That Grow Aerobically-Sixth Edition: Approved Standard M7-A6; NCCLS: Wayne, PA, USA, 2003.

21. Burt, S. Essential oils: Their antibacterial properties and potential applications in foodsA review. Int. J. Food Microbiol. 2004, 94, 223-253.

Sample Availability: Samples of the "Yimucao Oil", "Chongweizi Oil", and compounds $\mathbf{1 8}$ and $\mathbf{3 8}$ are available for experimental purposes from the authors.

(C) 2013 by the authors; licensee MDPI, Basel, Switzerland. This article is an open access article distributed under the terms and conditions of the Creative Commons Attribution license (http://creativecommons.org/licenses/by/3.0/). 